\title{
Investigation of Friction and Wear Performance of Diamond Coating under $\mathrm{Si}_{3} \mathrm{~N}_{4}$ Friction Pair
}

\author{
Feng LU*, Yueyao WANG**, Huixin LI***, Tianen HAO****, Zhengwei FU'****, \\ Guangyu YAN****** \\ *Shenyang Jianzhu University, Shenyang 110168, China,E-mail: lufeng72@126.com \\ **Shenyang Jianzhu University, Shenyang 110168, China,E-mail: mrwang2zs@163.com \\ ***Shenyang Jianzhu University, Shenyang 110168,China,E-mail:4754431915@qq.com \\ ****Shenyang Jianzhu University, Shenyang 110168,China,E-mail:1447674875@qq.com \\ *****Shenyang Jianzhu University, Shenyang 110168, China, E-mail: fuzhengwei0814@163.com \\ ******Shenyang Jianzhu University, Shenyang 110168, China, E-mail: 775083630@qq.com \\ crossref http://dx.doi.org/10.5755/j02.mech.28329
}

\section{Introduction}

Diamond coatings have gained increased attention in various fields owing to their excellent properties such as high hardness, low friction coefficient, high wear resistance, high elastic modulus, high thermal conductivity, chemical inertness, and good biocompatibility $[1,2]$. Consequently, diamond coatings have gained increased attention in the friction field because of their high hardness and low friction coefficient [3].

There are several methods for preparing diamond films, and tremendous efforts have been devoted to improving these methods. However, despite the improvements in these methods, several factors affect the friction properties of diamond coatings. Consequently, in the past few years, several researchers have studied diamond coatings from the macro-level to the micro-level. For example, several studies have investigated the effects of gas conditions, humidity and temperature, the materials of friction pair and substrate, lubrication conditions, and doping elements on the friction properties and wear mechanism of diamond coatings [4-8]. Gardos $[9,10]$ investigated the friction properties of diamond coatings deposited on $\mathrm{SiC}$ through the chemical vapor deposition (CVD) method using a reciprocating friction tester with a scanning electron microscope under different temperatures and gas conditions (vacuum, hydrogen, oxygen, and nitrogen). FIELD et al. [11] investigated the friction properties of diamond-like carbon (DLC) films prepared through an unbalanced magnetron sputtering system under loads of $20 \mathrm{~N}, 40 \mathrm{~N}, 60 \mathrm{~N}, 80 \mathrm{~N}$, and $100 \mathrm{~N}$. Chu et al. [12] analyzed the friction interface of DLC films ground with different ceramic pairs $\left(\mathrm{Si}_{3} \mathrm{~N}_{4}, \mathrm{SiC}, \mathrm{WC}, \mathrm{ZrO}_{2}\right.$, and $\mathrm{SiO}_{2}$ ). AJAYI et al. [13] investigated the friction properties of DLC films with $\mathrm{Si}$ doping under different conditions; Shen Bin et al. $[14,15]$ investigated and compared the properties of conventional diamond coatings and ultrafinegrained diamond coatings on cemented carbide under different lubrication conditions (dry friction and water lubrication) using reciprocating ball-disk friction and wear tester. The above results suggest that the friction properties of diamond coatings strongly depend on several conditions, aspects. Therefore, it is essential to clarify the influence of several factors on the friction properties of diamond coatings.

The properties of diamond prepared by hot filament chemical vapor deposition (HFCVD) are very similar to those of natural diamond [16], and this method has been extensively developed for the deposition of diamond coatings compared with other methods. Therefore, in this study, diamond coatings were deposited on cemented carbide using the HFCVD method, and the friction and wear properties of the diamond coatings under different methane concentrations, loads, and lubrication conditions were investigating.

\section{Materials and methods}

\subsection{Test materials}

In this study, cemented carbide (YG6) was used as the substrate. The YG6 is a circular substrate with a diameter of $25 \mathrm{~mm}$. During the CVD process, methane was used as the carbon source. The diamond coatings were prepared with methane concentrations of $1 \%, 2 \%, 3 \%, 4 \%$, and $5 \%$. The methane concentration parameters were set according to Table 1 .

Table 1

Carbon source concentration parameter setting

\begin{tabular}{|c|c|c|c|}
\hline $\begin{array}{c}\text { Substrate temper- } \\
\text { ature, }{ }^{\circ} \mathrm{C}\end{array}$ & $\mathrm{CH} 4, \mathrm{sccm}$ & $\mathrm{H} 2, \mathrm{sccm}$ & $\begin{array}{c}\text { Reaction } \\
\text { pressure, } \mathrm{kPa}\end{array}$ \\
\hline $850-900$ & 8 & 800 & 3.5 \\
\hline $850-900$ & 16 & 800 & 3.5 \\
\hline $850-900$ & 24 & 800 & 3.5 \\
\hline $850-900$ & 32 & 800 & 3.5 \\
\hline $850-900$ & 40 & 800 & 3.5 \\
\hline
\end{tabular}

There is a little cobalt on the surface of tungsten carbide, which will form graphite phase to restrain the growth of diamond grains under high temperature. Therefore, the substrate needs to be pretreated with acid and alkali to remove cobalt before preparing the diamond film. The substrate is sequentially placed in acetone, ultrapure water, and alcohol and sonicated for $5 \mathrm{~min}$ each. Afterward Murakamin's base solution (solution mass ratio $\mathrm{K}_{3}\left(\mathrm{Fe}(\mathrm{CN})_{6}\right)$ : $\mathrm{KOH}: \mathrm{H}_{2} \mathrm{O}=1: 1: 20$ ) is used to etch for 10 minutes to expose Co. Acid solution (solution volume ratio is $\mathrm{H}_{2} \mathrm{SO}_{4}: \mathrm{H}_{2} \mathrm{O}_{2}=$ $1: 10$ ) is used to etch for 1 minute to remove the exposed Co on the surface. Then, ultrasonic treatment was performed in a suspension of diamond for 30 minutes. Finally, ultrasonic treatment was performed with absolute ethanol for $3 \mathrm{~min}$. 


\subsection{Test plan and testing method}

The friction and wear tests were carried out on a Rtec-MFT5000 ball-to-disk friction and wear tester. For this test, the samples were cleaned for 5 min using an ultrasonic cleaning process (the solution was absolute ethanol) before each test. The temperature of the environment was normal (room temperature was $25^{\circ} \mathrm{C}$ and humidity was $32 \%$ ).

Under water lubrication conditions, the friction pair, which is a silicon nitride $\left(\mathrm{Si}_{3} \mathrm{~N}_{4}\right)$ ball with a diameter of $6 \mathrm{~mm}$, was completely immersed in deionized water. To obtain the friction coefficient curve that changes with the friction process, the signal transmitted to the controller through the sensor during the friction and wear test process was used. The formula is as follows:

$$
\mu=\frac{F}{S}
$$

where: $F$ is the force of the friction, N; $S$ is the normal load, $\mathrm{N} ; \mu$ is the friction coefficient.

Table 2

Friction and wear test parameters

\begin{tabular}{|c|c|c|c|c|c|}
\hline Test conditions & Load, N & Frequency, HZ & Time, $\mathrm{s}$ & Test Bench & Methane concentration \\
\hline Dry friction & 5 & 10 & 1800 & Spin & $1 \%-5 \%$ \\
\hline Dry friction & 10 & 10 & 1800 & Spin & $1 \%-5 \%$ \\
\hline Dry friction & 15 & 10 & 1800 & Spin & $5 \%$ \\
\hline Dry friction & 5 & 2 & 1800 & Back and forth & $3 \%$ \\
\hline Water lubrication & 5 & 2 & 1800 & Back and forth & $3 \%$ \\
\hline
\end{tabular}

A field emission scanning electron microscope (FESEM, HITACHI SU-70 SEM) was used to observe the morphology and worn surfaces of the samples. High-resolution Raman spectroscopy was used to characterize the microstructure of the coating before and after the test. An optical microscope was used to investigate the wear scar fracture. A probe surface profiler was used to measure the sample, evaluate the wear scar morphology, and calculate the corresponding wear rate based on the measured cross-sectional profile and wear scar stroke, using the formula:

$$
W=\frac{V}{S L},
$$

where: $W$ is the wear rate, $\mathrm{mm}^{3} / \mathrm{Nm} ; V$ is the wear volume, $\mathrm{mm}^{3} ; S$ is the normal load, $\mathrm{N} ; L$ is the total wear stroke, $\mathrm{mm}$.

\section{Results and discussion}

\subsection{Morphology of the film}

Diamond coating films prepared at $1 \%, 3 \%$, and $5 \%$ methane concentrations were selected to analyze the influence of different methane concentrations on the film preparation.Fig. 1 are the surface morphologies of diamond films prepared at a methane concentration of $1 \%, 3 \%$, and $5 \%$, respectively. When the methane concentration was $1 \%$, the diamond grain size was about 3-5 $\mu \mathrm{m}$, and the exposed faces were oriented (111) and (100) faces. There was no accumulation of fine crystal clusters, indicating that the formation of high quality Micron-sized diamond (MCD). When the methane concentration was increased to $3 \%$, the typical $<111>$ crystal planes disappeared, the diamond grains in the film were refined, there were micron grains and a large number of nano grains, indicating that it became submicron diamond (SMCD). When the methane concentration is increased to $5 \%$, the grain size was about tens of nanometers, and the grain size was uniform, indicating that it completely became nano-diamond (NCD). Overall, it showed that as the methane concentration increases, it was beneficial to reduce the surface roughness of the film.
3.2. Effect of different methane concentration on friction behavior of diamond coatings

Fig. 2 shows the friction coefficient curve of the diamond coating under a load of $5 \mathrm{~N}$. As shown in the figure, the test process can be divided into three stages: the initial stage, the run-in stage, and the stable stage. The initial stage can be attributed to the relatively insufficient smoothness of the surface between the friction pair and the diamond coating. This is because there was a large number of protrusions of large micron particles on the friction surface. During the grinding process of the diamond coating with the $\mathrm{Si}_{3} \mathrm{~N}_{4}$ ball, the protrusion of the friction surface induced a mechanical interlocking that caused a plowing effect on the surface of the ceramic ball with low hardness, resulting in a high friction coefficient.

During the friction tests, furrow and abrasive chips were observed on the surface of the $\mathrm{Si}_{3} \mathrm{~N}_{4}$ balls under the plowing effect. The corresponding wear was classified as abrasive. Because the friction test was carried out for a long time under long-term shear stress, the surface of the diamond coating fractured. Subsequently, the large particles on the surface of the diamond coating fell off. Two types of debris stuck together during the friction process to form a smooth intermediate film because of the long-term normal pressure and rotating motion. In addition, the two materials showed a cushioning effect during the friction process.

After the run-in stage, the interlocking effect between the diamond coating and the $\mathrm{Si}_{3} \mathrm{~N}_{4}$ ball slowly reached a relatively stable stage, resulting in the decrease and stabilization of the friction coefficient.

As shown in Fig. 2, when the methane concentration was $1 \%$, there were large local fluctuations in the stable stage, indicating that the grain size of the diamond coating at $1 \%$ methane concentration was large. These particles were not completely squeezed during friction. Therefore, after the run-in stage, there were still a few particles on the friction interface. During the friction test, these particles rotated freely, thus resulting in the local mutation of the friction coefficient in the stable stage. When the methane concentration was increased to $2 \%$, the friction coefficient was more stable than at the concentration of $1 \%$, but there were still some local sudden fluctuations, indicating a decrease in 
the grain size of the diamond coating. When the methane concentration was further increased to $3 \%$, the run-in stage time decreased. In addition, there was no sign of fluctuations in the stable stage. As shown in Fig. 6, the grain size of the diamond coating was reduced to a sub-micron level, thus decreasing the surface roughness and friction coefficient of the coating. When the methane concentration was further increased to $4 \%-5 \%$, the friction coefficient suddenly increased. This is because with an increase in the methane concentration, although the grain size of the diamond coat-

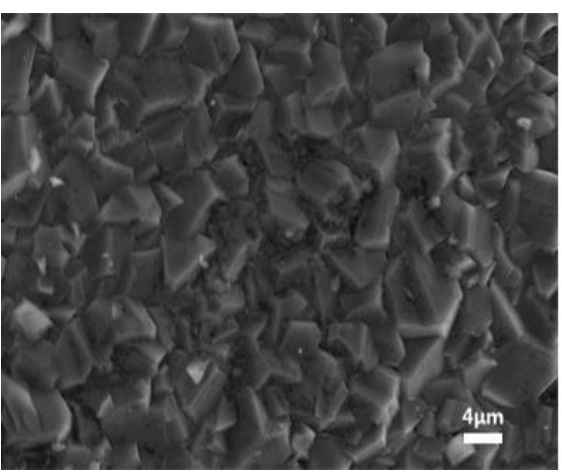

a) $1 \%$

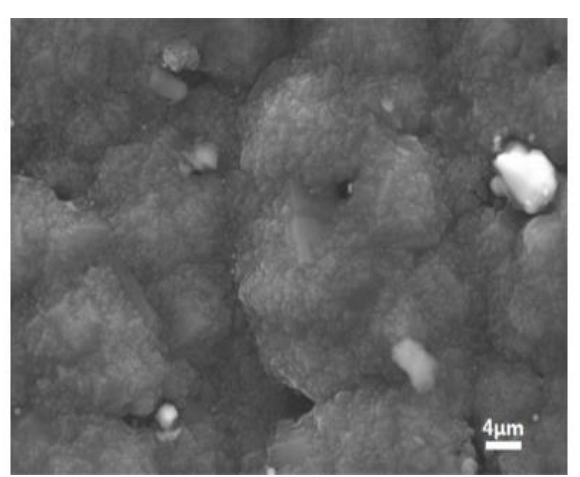

b) $3 \%$ ing decreased, there were several $\mathrm{sp}^{2}$ hybrid bonds in the diamond coatings, which decreased the adhesion between the diamond coating and substrate. Compared with the others, the sample prepared under 5\% methane concentration had an obvious tendency to increase, and had a longer run-in stage. This is because, with an increase in the friction test time, the adhesion reduced rapidly, and thus the coating fell off. Consequently, the residual wear debris increased, thus increasing the run-in stage time.

Fig. 1 SEM morphology of diamond films under different methane concentrations

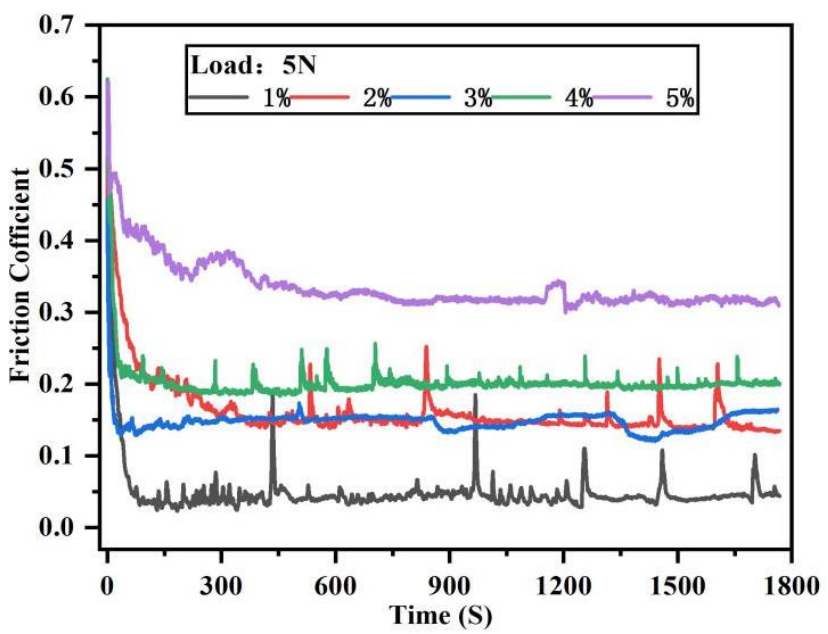

Fig. 2 Friction coefficient of diamond coating under a load of $5 \mathrm{~N}$

3.3. The influence of different loads on friction behavior of diamond coatings

Fig. 3 shows the friction coefficient graph of the diamond coatings prepared under different methane concentrations under a load of $10 \mathrm{~N}$. As shown in Fig. 3, the friction coefficient of the diamond coating decreased with an increase in the load. This is because the heat and the contact stress during the friction process increased with an increase in the load. Consequently, local graphitization occurred between the diamond coating and friction pair during the friction process. Because graphite has a simple lubricating effect, the friction coefficient of the coatings reduced dramatically. In addition, the graphitized layer rotates with the friction pair movement, which also affected the friction properties.

Fig. 4 shows the friction coefficient of the diamond coatings prepared at 5\% methane concentration under different loads $(5 \mathrm{~N}, 10 \mathrm{~N}$, and $15 \mathrm{~N})$. Fig. 5 , $\mathrm{a}$ and $\mathrm{b}$ are the

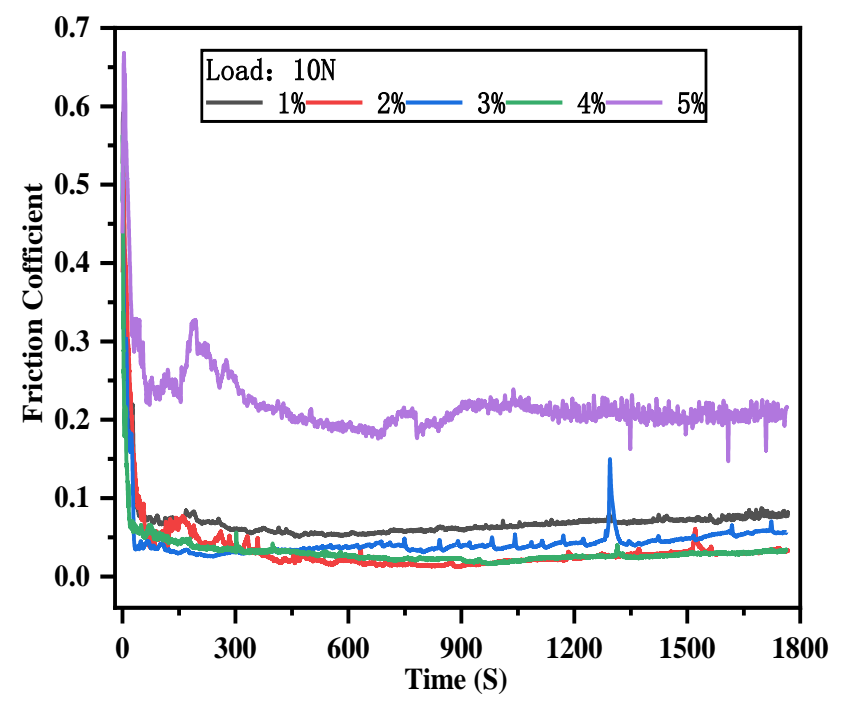

Fig. 3 Friction coefficient of the film under a load of $10 \mathrm{~N}$

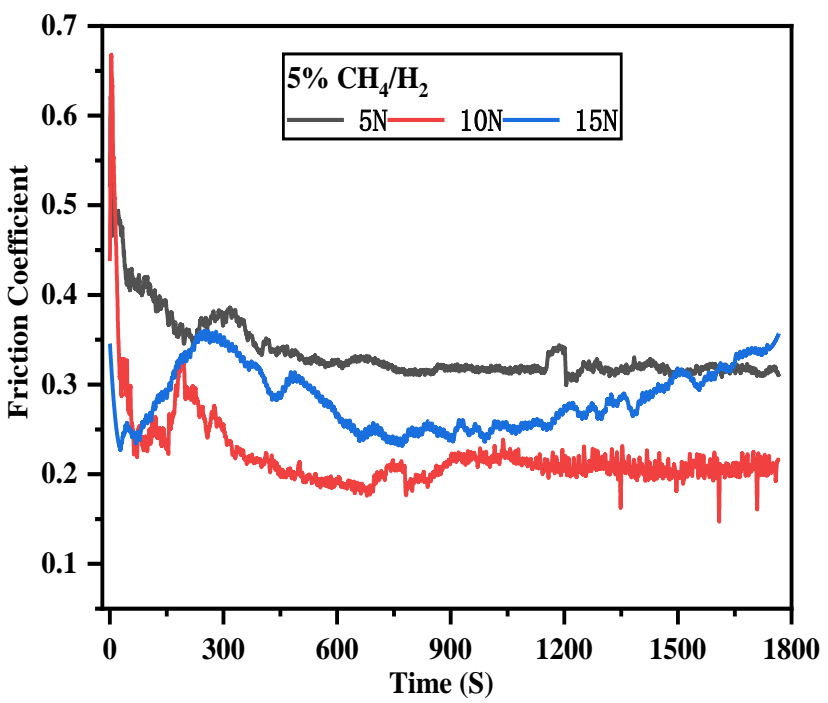

Fig. 4 Coefficient of friction of the film under different loads 
wear morphology under $5 \mathrm{~N}$ and $15 \mathrm{~N}$ loads, respectively. From the two figures, it can be inferred that the friction coefficient of the diamond coating under 5\% methane concentration was stable under loads of $5 \mathrm{~N}$ and $10 \mathrm{~N}$. However, the friction coefficient under $15 \mathrm{~N}$ was extremely unstable and fluctuated greatly, indicating that the ability of the diamond coating with 5\% methane concentration to bear loads is weak. This suggests that the sample may have reached a critical load of failure. This is because when the initial stage was reached, the coating would bear a normal pressure of $15 \mathrm{~N}$. The ceramic ball caused an excessive normal load on the coating simultaneously, thus damaging the surface of the diamond coating due to the rapid rotation under shear stress.

Consequently, the extreme impact caused severe peeling of the coating, which led to coating failure.

3.4. The influence of water lubrication conditions on friction behavior of diamond coatings

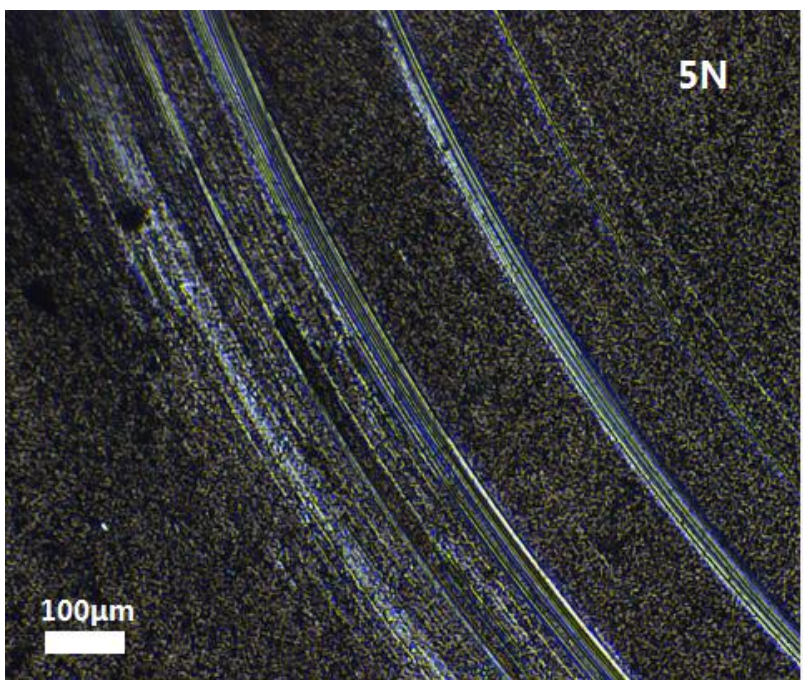

a) $5 \mathrm{~N}$

\subsubsection{The organizational structure of the coating}

The above comparison and analysis indicate that the coating prepared under a methane concentration of $3 \%$ showed the best properties. Therefore, the diamond coating prepared under 3\% methane concentration was used for the friction and wear tests under dry and water lubrication conditions.

As shown in Fig. 6, the diamond coating exhibited an obvious diamond Raman D peak at $1334 \mathrm{~cm}^{-1}$, indicating that the carbon in the film was mainly combined in the $\mathrm{sp}^{3}$ mode. In addition, additional strong peaks were observed at $1131 \mathrm{~cm}^{-1}$ and $1469 \mathrm{~cm}^{-1}$. Furthermore, broad scattering peaks were observed in the Raman spectrum, indicating that the grains have trans-polyethylene characteristics. In addition, the grain boundary density increased, suggesting that the sample was composed of nanocrystalline [17].

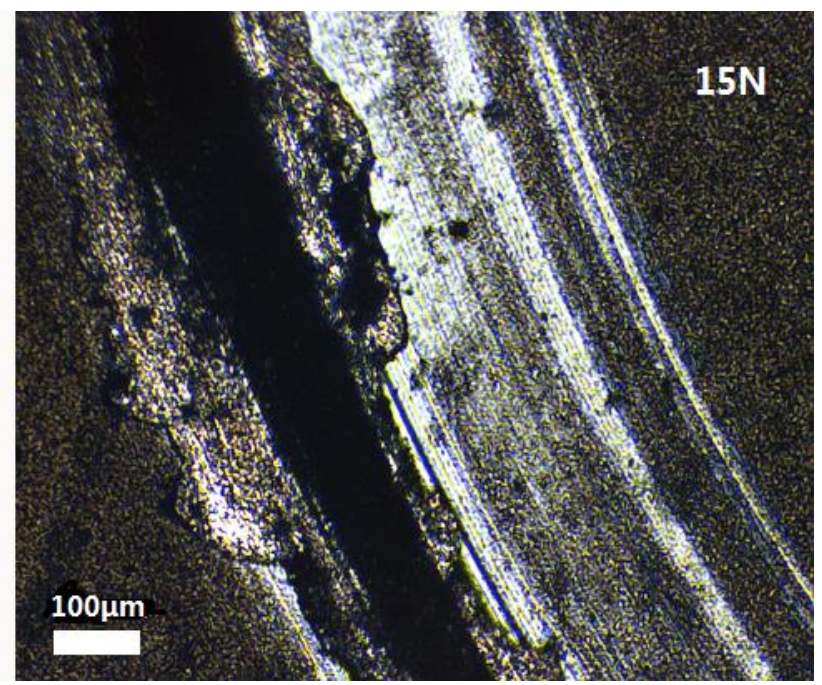

b) $10 \mathrm{~N}$

Fig. 5 Wear morphology of the film under different loads

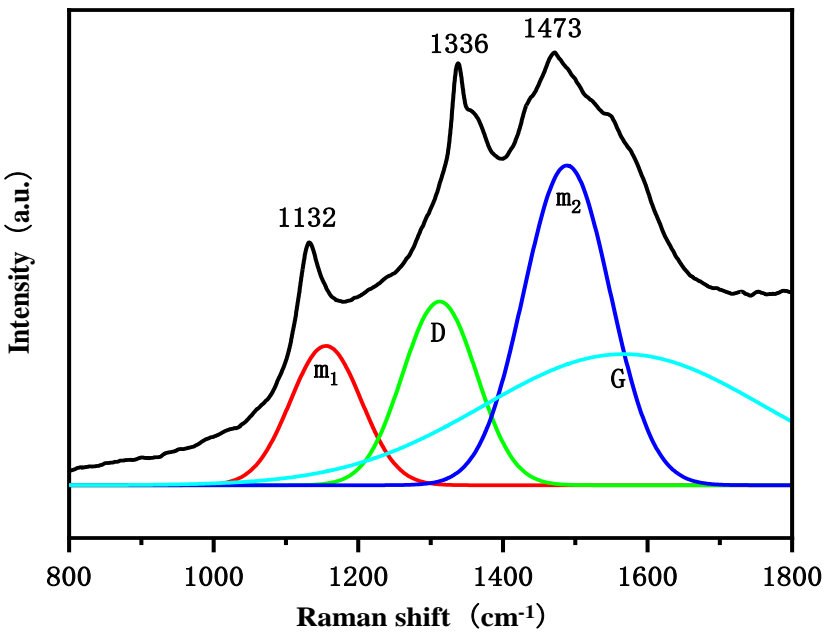

Fig. 6 Raman spectrum of the diamond coating

\subsubsection{Friction properties of the coating}

Fig. 7 shows the friction coefficient curves of the diamond coating prepared under $3 \%$ methane concentration under the two conditions (dry and water lubrication) and a comparison of the friction coefficients between the initial and stable stage. A comprehensive comparison shows the influence of water lubrication on the friction properties of the coating. The maximum friction coefficient of the coating under dry friction condition in the initial stage was 0.424 , whereas that under the water lubrication condition was 0.325 . This is because the boundary water film formed on the friction interface under water lubrication condition at the beginning of the friction test reduced the shear strength of the contact surface and the initial friction coefficient. Furthermore, the run-in stage of the diamond coating under dry friction condition was approximately $1200 \mathrm{~s}$, whereas that under water lubrication condition was approximately $300 \mathrm{~s}$. Moreover, the friction coefficient under dry friction fluctuated considerably. This is because dripping lubrication was used in this test. After several drippings, the diamond grinding and $\mathrm{Si}_{3} \mathrm{~N}_{4}$ ball grinding debris generated in the initial stage moved to the water flow and flowed out of the friction interface.

A small amount of the grinding debris and water form a water film that considerably reduced the roughness of the diamond coating surface during the wear process and minimizes the actual contact area of the friction pair, thus reducing the time from the run-in stage to the stable stage and decreasing the coefficient of friction. In the stable stage, the average friction coefficients under dry friction and water 
lubrication conditions were 0.107 and 0.065 , respectively. In summary, it can be concluded that the water lubrication

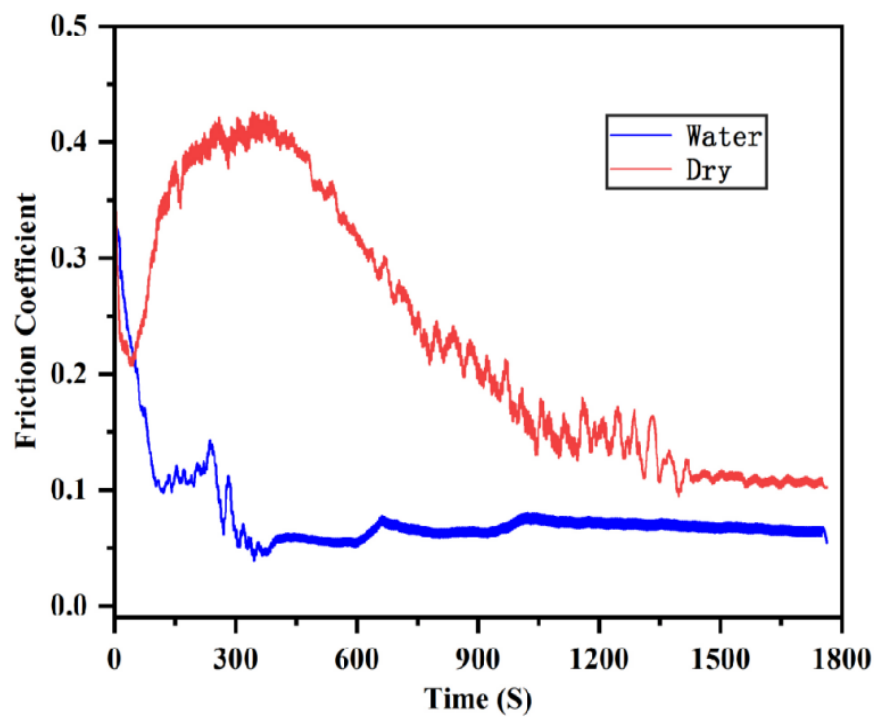

a) Friction curve condition had a lubricating effect throughout the friction process and effectively reduced the friction coefficient.

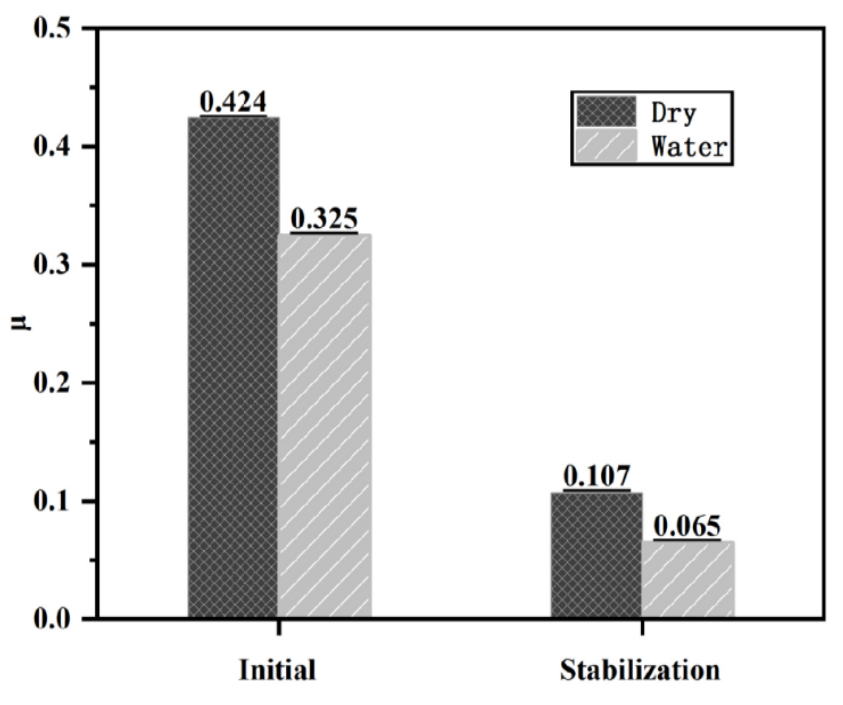

b) Friction coefficient

Fig. 7 Friction coefficient of the coatings under different lubrication conditions

Fig. 8 shows the morphology of the cross-section of the wear scar on the coating surface obtained through a probe-type surface profiler. A three-time fitting curve was obtained through the wear curve. As shown in Fig. 8, the width of the wear scar was approximately $900 \mu \mathrm{m}$. In addition, the wear scar under dry friction conditions was more severe, and the surface of the wear scar was smooth. The

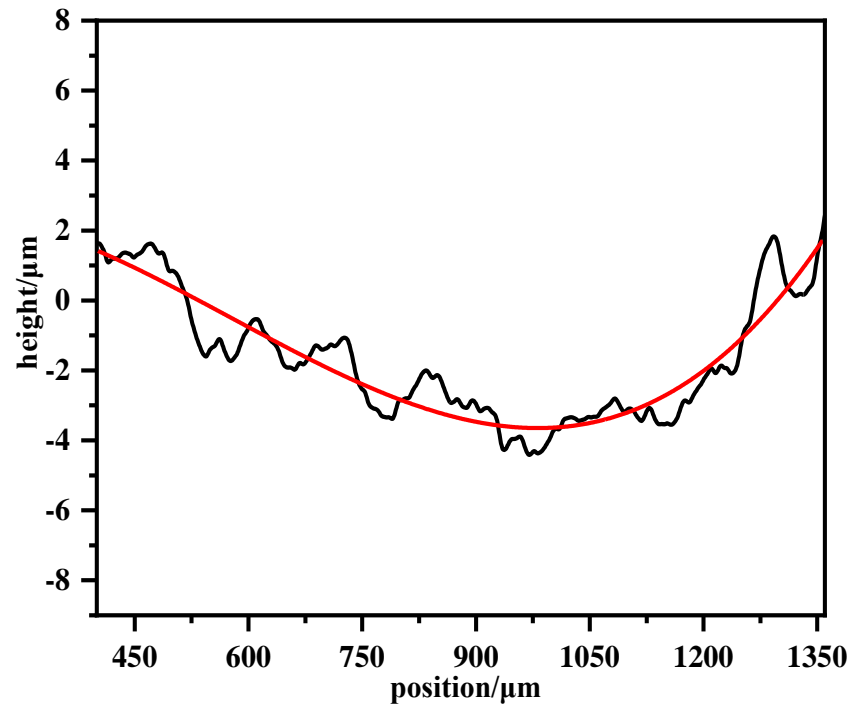

a) Dry friction conditions wear rate calculated through the curve was $1.06 \times$ $10^{-8} \mathrm{~mm}^{3} /(\mathrm{Nm})$. By contrast, the surface of the wear scar under water lubrication was rougher. However, the wear rate of the coating under water lubrication condition was significantly reduced compared with the coating under the dry friction condition.

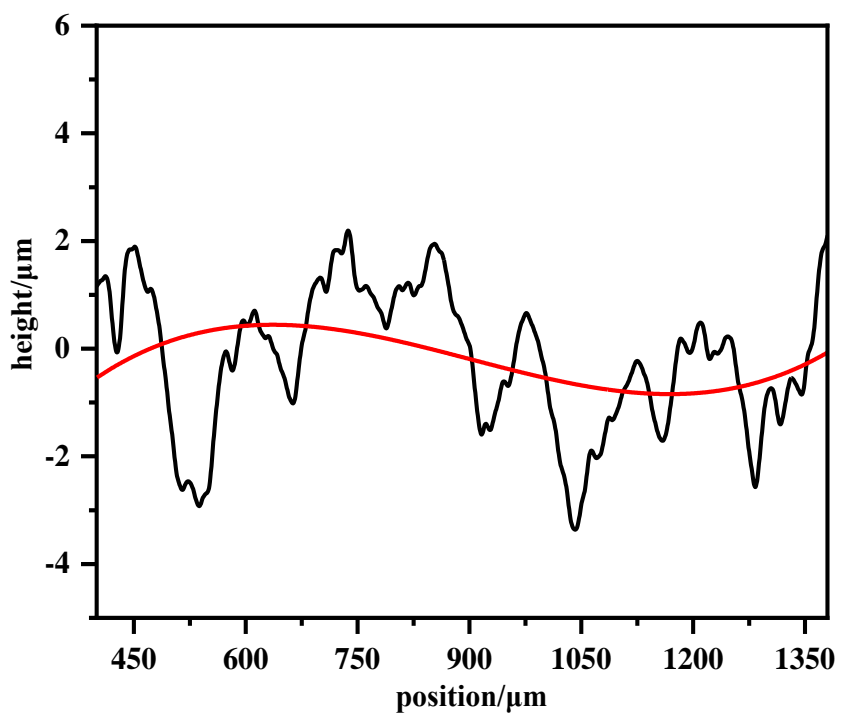

b) Water lubrication conditions

Fig. 8 Cross-section morphology of wear scar of thin film

\subsubsection{Raman spectrum of the wear scar}

Figs. 9, $\mathrm{a}$ and $\mathrm{b}$ show the Raman spectrum of the wear scar under the dry friction and water lubrication conditions, respectively. As shown in Fig. 9, a, an obvious peak was observed at $1551 \mathrm{~cm}^{-1}$ in the Raman spectra of the initial film under dry friction conditions, indicating that there were a large number of $\mathrm{sp}^{2}$ hybrid bonds, which are generally referred to as graphite peaks. This is due to the long-term re- ciprocating friction test, and heat generation, which caused graphitization on the surface of the coating. As shown in Fig. 9, b, there was no significant change in the Raman spectrum of the film under water lubricating condition compared with that of the original film, indicating that the water lubrication condition did not only effectively reduce the friction coefficient but also reduced the graphitization phenomenon caused by the temperature. These results confirm the integrity of the film. 


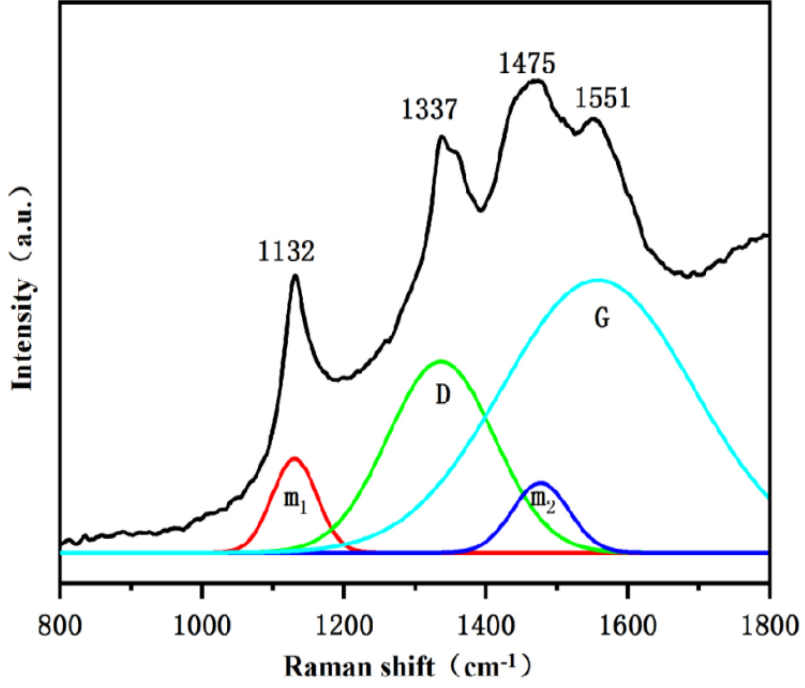

a) Wear scar under dry friction

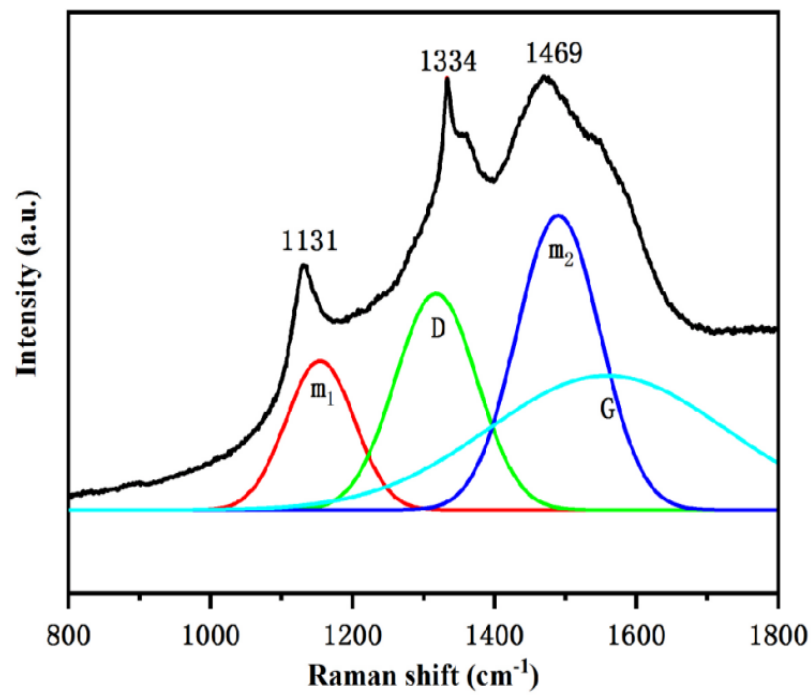

b) water lubrication conditions

Fig. 9 Raman spectrum of the wear scar

\subsubsection{Wear profile analysis}

To investigate the friction and wear mechanism of the diamond coatings prepared at a methane concentration of $3 \%$ under the water lubrication and dry conditions, SEM and three-dimensional profile morphology observations

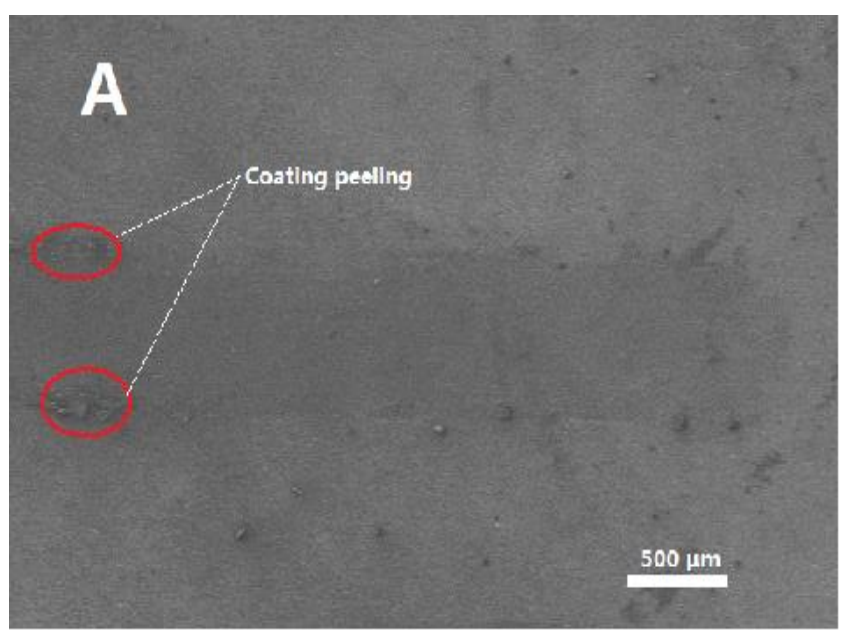

were performed on the wear scar after the test was completed. As shown in Fig. 10, under a load of $5 \mathrm{~N}$, the degree of wear under the two conditions was not significant, which indicates the high hardness and good wear resistance of the diamond coating.

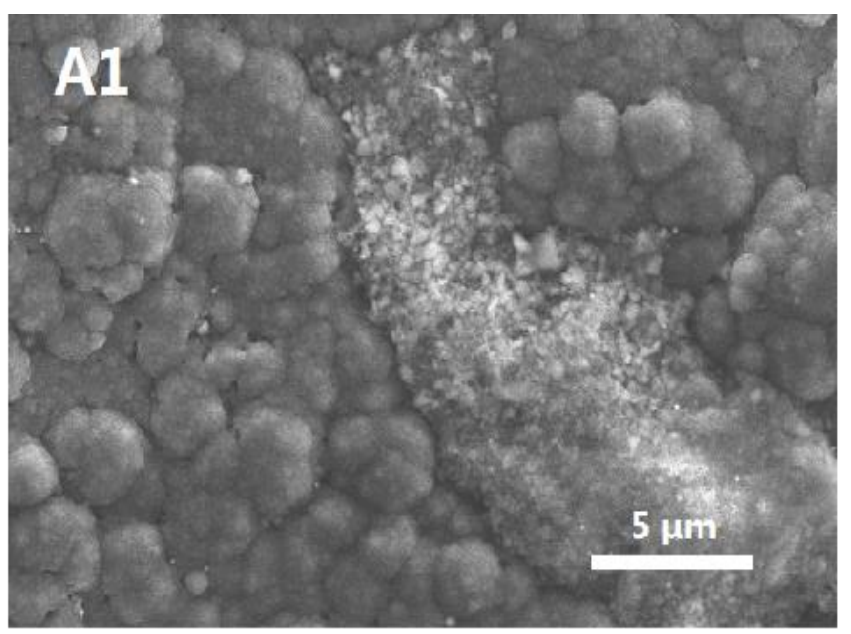

a) Dry friction conditions
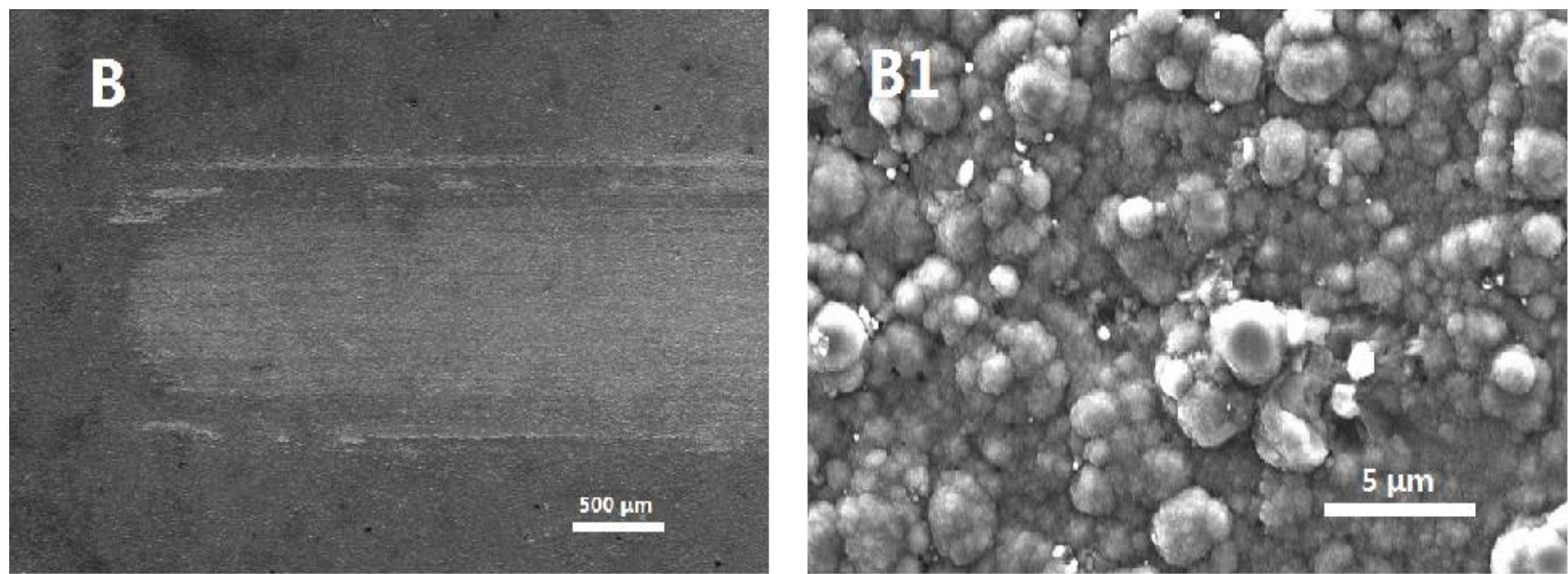

b) Water lubrication conditions

Fig. 10 SEM morphology of the film after wear 
However, the comparison of the coatings under the two conditions indicate that the dry friction condition has a greater wear degree. In addition, some furrows were observed in the film, and some other things are doped. The A1 picture in Fig. 10 is the SEM of the place where the coating falls off. It can be seen that the part may be doped with some other substances. The Raman spectrum in Fig. 9 suggests that the furrows were $\mathrm{Si}_{3} \mathrm{~N}_{4}$ wear debris or graphite. However, no wear was observed in the film under water lubrication conditions. This is because when $\mathrm{Si}_{3} \mathrm{~N}_{4}$ is ground in water, chemical reactions occur and the product covers the wear scar through reciprocating motion, which acts as a lubricating film. This result is consistent with the friction coefficient curve.

\section{Conclusion}

This paper proposes the difference of changing the carbon source, analyzes the tribological properties of the diamond coating after preparation, and uses the diamond film prepared with the optimal carbon source parameters to analyze the effect of different lubrication conditions on the friction properties of the coating. The following conclusions can be drawn from this study:

1. Diamond coatings were prepared at different methane concentrations $(1 \%, 2 \%, 3 \%, 4 \%$, and $5 \%)$ to investigate the effect of methane concentration on the properties of the diamond coatings. The results revealed that the diamond coating with $3 \%$ methane concentration was composed of nanocrystalline. In addition, the friction coefficient of the diamond coating prepared under 3\% methane concentration was relatively stable. However, the adhesion between the diamond and the substrate decreased with a further increase in the methane concentration.

2 . The friction process of the diamond coating prepared under a methane concentration of $5 \%$ was more stable under loads of $5 \mathrm{~N}$ and $10 \mathrm{~N}$ than under a load of $15 \mathrm{~N}$. This can be attributed to the reduced adhesion between diamond and substrate when the methane concentration is $5 \%$. Consequently, the ability of the coating to bear the load was weak, and the failure load of the diamond coating may have been reached under a load of $15 \mathrm{~N}$.

3. Under water lubrication conditions, the shear strength on the friction interface was reduced. In addition, a good lubricating film was formed on the surface of the coating, which effectively reduced the formation of abrasive wear and the friction coefficient. Based on this phenomenon, the wear process can quickly get stable. The friction coefficient in the stable stage was reduced by 0.042 compared to dry friction conditions. In addition, the wear rate under the water lubrication condition was reduced by 4 to 5 times compared to dry friction conditions

\section{Acknowledgments}

This thesis is Sponsored by Liaoning Natural Science Foundation (20170540757); Program for Science and Technology Innovation Talents of Young and middle-aged of Shenyang (SYSCXRC2017002). Key projects of Liaoning Provincial Department of Education(lnzd202002).

\section{References}

1. Lu, F. X. 2014. Preparation and Application of Diamond
Film, 1 nd Edition, Science Press., China, Beijing, ISBN 9787030418227.

2. Jin, H. Z.; Shi, X. W. ; et al. 2009. Research progress on the tribological properties of diamond films, Vacuum 46(3): 31-37. https://CNKI:SUN:ZKZK.0.2009-03-014.

3. Wu, J. L.; Zhou, H.; Zheng, J.; Yang, L. M.; et al. 2015. The influence of $\mathrm{H}_{-} 2 / \mathrm{CH}_{-} 4$ flow ratio on the structure and tribological properties of hydrogen-containing DLC film, China Surface Engineering 28(1): 4248.

https://doi.org/10.11933/j.issn.1007-9289.2015.01.007.

4. Yong, Q. S.; Wang, H. D.; Xu, B. S.; Ma, G. Z. 2016. The research status of the friction mechanism and the influencing factors of the tribological properties of diamond-like carbon films, Journal of Mechanical Engineering 52(11): 95-107.

https://doi.org/10.3901/JME.2016.11.095.

5. Sun, H. T.; Wang, X. P.; Wang, L. J.; et al. 2014. Research status of tribological properties of CVD diamond film, Materials Review, 28(5): 47-52+73. https://doi.org/10.3969/j.issn.1005-023X.2014.05.010.

6. Han, X. X.; Yan, P. X.; Yan, F. Y.; Liu, W. M. 2003. Friction characteristics of diamond-like carbon coatings under different loads and humidity, Tribology 1: 5-9. https://doi.org/10.3321/j.issn:1004-0595.2003.01.002.

7. Zhang, R. H.; Lu, Z. B.; Wang, L. P. 2016. The influence of load on the tribological properties of fluorinesilicon co-doped diamond-like carbon film, Tribology 36(1): 84-91. https://doi.org/10.16078/j.tribology.2016.01.013.

8. Wu, X. Y.; Chen, T.; Ge, Z.; Ruan, J. J.; Lu, B.; Zhang, J. H. 2017. Study on the tribological properties of $\mathrm{N}$ and Si co-doped DLC films under different humidity conditions, Tribology 37(4): 501-509.

https://doi.org/10.16078/j.tribology.2017.04.012.

9. Gardos, M. N.; Gabelich, S. A. 1999. Atmospheric effects of friction, friction noise and wear with silicon and diamond, Part I, Test methodology, Tribology Letters 6(2): 79-86.

https://doi.org/10.1023/A:1019151405021.

10. Gardos, M. N.; Gabelich, S. A. 1999. Atmospheric effects of friction, friction noise and wear with silicon and diamond, Part III, SEM tribometry of polycrystalline diamond in vacuum and hydrogen, Tribology Letters 6(2): 103-112. https://10.1023/A:1019147304112.

11. Field, S. K.; Jarratt, M.; Teer, D. G. 2004. Tribological properties of graphite-like and diamond-like carbon originated from a unique fullerene-like nanostructure, Nanotechnology 37: 949-956.

https://doi.org/10.1016/j.triboint.2004.07.012.

12. Chu, P. K.; Li, L. H. 2005. Characterization of amorphous and nanocrystalline carbon films, Materials Chemistry and Physics 96(2-3): 253-277. https://doi.org/10.1016/j.matchemphys.2005.07.048.

13. Ajayi, O. O.; Kovalchenko, A.; Hersberger J. G.; et al. 2003. Surface damage and wear mechanisms of amorphous carbon coatings under boundary lubrication conditions, Surface Engineering 19: 447-453. https://doi.org/10.1179/026708403225010181.

14. Shen, B.; Sun, F. H.; Zhang, Z. M. 2008. Study on the friction and wear properties of CVD diamond film under water lubrication conditions, Tribology 2: 112-117. 
https://doi.org/10.3321/j.issn:1004-0595.2008.02.004.

15. Shen, B. 2012. Preparation, tribological properties and application research of ultra-smooth diamond composite film, Journal of Mechanical Engineering 48(18): 185. https://doi.org/CNKI:SUN:JXXB.0.2012-18-033.

16. Liu, L. S.; Chen, X. D.; Tian, Q. Q.; et al. 2016. Research progress and prospects of diamond-coated tools, Vacuum 53(2): 18-20.

https://doi.org/10.13385/j.cnki.vacuum.2016.02.05.

17. Dumpala, R.; Kumar, N.; Kumaran, C. R.; et al. 2014. Adhesion characteristics of nano- and micro-crystalline diamond coatings: Raman stress mapping of the scratch tracks, Diamond \& Related Materials 44(4): 71-77. https://doi.org/10.1016/j.diamond.2014.02.007.

\section{F. Lu, Y. Wang, H. Li, T. Hao, Zh. Fu, G. Yan}

\section{INVESTIGATION OF FRICTION AND WEAR PER- FORMANCE OF DIAMOND COATING UNDER SI3N4 FRICTION PAIR}

S u m m a r y

In this study, diamond coatings were deposited through the hot filament chemical vapor deposition method on cemented carbide under different methane concentrations, ranging from $1 \%$ to $5 \%$, to analyze the performance of the diamond coatings under different loads and lubrication conditions. Friction and wear tests were carried out using ball-disk friction and wear tester under different loads and lubrication conditions. Scanning electron microscopy, high-resolution Raman spectrometry, optical microscopy, and a surface profiler were used to observe the surface morphology and quality of the coatings after the wear test. The results revealed that the coating prepared under $3 \%$ methane concentration was more stable during the friction test than that prepared under other methane concentrations. In addition, the coating prepared under $5 \%$ methane concentration had poor adhesion and experienced failure under excessive load. Furthermore, lubricating the friction surface with water effectively reduced the formation of abrasive wear and the friction coefficient, and thus the sample reached the stable stage faster. In addition, the wear rate of the coating under wet condition was approximately 4-5 times less than that under dry friction conditions.

Keywords: methane concentration; run-in stage; friction coefficient; surface morphology.

Received January 19, 2021 Accepted October 04, 2021 